\title{
Tuberculosis in National Health Service hospital staff in the West Midlands region of England, 1992-5
}

\author{
Adam Hill, Anne Burge, Craig Skinner
}

\begin{abstract}
Background - This study was designed to assess the current incidence of tuberculosis (TB) in National Health Service hospital staff in the West Midlands region of England and to evaluate the effectiveness of occupational health screening and surveillance procedures.

Methods - A four year prospective study (1992-5) was carried out with case ascertainment through occupational health departments and the Midlands Thoracic Society registry of rare respiratory diseases.
\end{abstract}

Results No case was known to an occupational health department that was not notified by the registry and, in addition, the registry yielded a further six cases. There were 26 cases of active TB, of which 24 presented with symptoms and 12 had no pre-employment screening. All except one doctor were foreign born - mainly from the Indian subcontinent (ISC) - and of recent UK entry, whilst all except one nurse were white females. The following are annual TB incidences per $10^{4}(95 \%$ confidence interval): ISC and non-white doctors 17.0 (7.8 to 26.2 ), not significantly greater than in the local ISC and nonwhite social class 1 working age population (11.8 (8.5 to 15.1)); white nurses $0.6(0.2$ to 1.0$)$, significantly greater $(p<0.05)$ than that of white women in the local social class 2 working age population $(0.2)(0.1$ to $0.3)$ ); others (mortuary attendant, physiotherapist, radiographer and theatre technician) 1.0 (0.02 to 2.0$)$, not significantly greater than in the local social class 2 working age population (0.6 (0.5 to 0.7$))$.

Conclusions - Case ascertainment via the registry was complete. Most cases of TB were in nurses and doctors, more commonly in doctors. However, all but one of the doctors were foreign born and probably had reactivation of infection acquired abroad rather than infection occupationally acquired in the UK. All but one of the nurses, however, were UK born and may have had occupationally acquired disease, their incidence being higher than in the community. As most cases present with symptoms, there needs to be continued emphasis on prompt reporting of suspicious symptoms both before and during employment, and pre-employment BCG vaccination where appropriate.

(Thorax 1997;52:994-997)

Keywords: tuberculosis, National Health Service hospital staff, occupational surveillance.

Tuberculosis (TB) is a prescribed occupational disease for health care workers. In a health care setting infection usually arises from repeated close contact with patients who have sputum smear-positive pulmonary disease, or with infected laboratory specimens or necroscopic material. A study in England and Wales in the 1980s showed that the incidence of TB was similar to or lower than that of the general population for all occupational groups except mortuary attendants, ${ }^{1}$ whilst a Scottish study showed similar findings with only medical laboratory technicians having an increased incidence. ${ }^{2}$ The risk to mortuary workers was again highlighted more recently. ${ }^{3}$ In contrast to previous reports, however, a recent study suggested that the incidence of TB is increased in all health service staff in England and Wales. ${ }^{4}$

In this study we have assessed the current incidence of tuberculosis in National Health Service hospital staff in the West Midlands region of England and evaluated the effectiveness of occupational health screening and surveillance procedures.

\section{Methods}

A four year prospective study was undertaken from January 1992 to December 1995. During this period, through the Association of National Health Service Occupational Physicians, a system was in place for recording the occurrence throughout the West Midlands of TB in hospital staff. Because cases of TB in health care workers may not always be known to the Occupational Health Department, a backup case ascertainment system was set up using the Midland Thoracic Society rare diseases registry. All respiratory physicians in the region submit monthly returns of selected rare respiratory diseases, including TB in health care workers, during the study period. It was assumed that TB in health care workers would be treated by respiratory physicians and would thus be reported through the registry.

For the purposes of the registry TB in health care workers was defined as TB, pulmonary or otherwise, for which full chemotherapy was 
Table 1 Nurses with tuberculosis

\begin{tabular}{|c|c|c|c|c|c|c|c|c|c|}
\hline $\begin{array}{l}\text { Case } \\
\text { no. }\end{array}$ & Specialty & Referral & $\begin{array}{l}\text { Ethnic } \\
\text { group }\end{array}$ & $\begin{array}{l}\text { Age } \\
\text { (years) }\end{array}$ & Sex & $\begin{array}{l}\text { Prior } \\
\text { BCG }\end{array}$ & $\begin{array}{l}\text { Heaf grade pre- } \\
\text { employment }\end{array}$ & $\begin{array}{l}\text { Heaf grade at } \\
\text { presentation }\end{array}$ & Diagnosis \\
\hline 1 & Thoracic surgery & Sumptoms & Black Caribbean & 44 & $\mathrm{~F}$ & No & 2 & 4 & Hilar lymph nodes \\
\hline 2 & Student nuse & Symptoms & White & 28 & $\mathrm{~F}$ & Yes & 2 & Not done & Cervical lymph nodes \\
\hline 3 & Hospice & Symptoms & White & 40 & $\mathrm{~F}$ & No & 1 & Not done & SMCN PTB \\
\hline 4 & Respiratory medicine & Symptoms & White & 60 & $\mathrm{~F}$ & Yes & 0 & Not done & SMP PTB \\
\hline 5 & Elderly care & Symptoms & White & 30 & $\mathrm{~F}$ & Yes & 0 & 4 & SMCN PTB \\
\hline 6 & General medicine & Symptoms & White & 28 & $\mathrm{~F}$ & Yes & Not done & Not done & SMP PTB \\
\hline 7 & Elderly care & Symptoms & White & 44 & $\mathrm{~F}$ & Yes & Not done & 0 & SMCP PTB \\
\hline 8 & Psychiatry & $\begin{array}{l}\text { Occupational } \\
\text { surveillance }\end{array}$ & White & 43 & $\mathrm{~F}$ & Yes & 1 & 4 & Lung tuberculoma \\
\hline
\end{tabular}

SMP PTB = sputum smear positive pulmonary tuberculosis; SMCP PTB=sputum smear negative but culture positive pulmonary tuberculosis; $\mathrm{SMCN}$ PTB = sputum smear and culture negative pulmonary tuberculosis.

Table 2 Doctors with tuberculosis

\begin{tabular}{|c|c|c|c|c|c|c|c|c|c|c|}
\hline $\begin{array}{l}\text { Case } \\
\text { no. }\end{array}$ & Specialty & Referral & $\begin{array}{l}\text { Ethnic } \\
\text { group }\end{array}$ & $\begin{array}{l}\text { Years } \\
\text { in UK }\end{array}$ & $\begin{array}{l}\text { Age } \\
\text { (years) }\end{array}$ & Sex & $\begin{array}{l}\text { Prior } \\
B C G\end{array}$ & $\begin{array}{l}\text { Heaf grade } \\
\text { pre-employment }\end{array}$ & $\begin{array}{l}\text { Heaf grade } \\
\text { at presentation }\end{array}$ & Diagnosis \\
\hline 9 & Geriatrics & Symptons & ISC & NK & 31 & $\mathrm{~F}$ & Yes & Not done & 3 & Hilar lymph nodes \\
\hline 10 & Radiotherapy & Symptoms & ISC & 15 & 57 & M & NK & Not done & Not done & Laryngeal \\
\hline 11 & Medicine & Symptoms & ISC & 3 & 28 & M & No & Not done & Not done & SMP PTB \\
\hline 12 & Obstetrics & Symptoms & ISC & 4 & 26 & M & Yes & 2 & 3 & Pleural \\
\hline 13 & Geriatrics & Symptoms & Malaysian & 11 & 39 & $\mathrm{~F}$ & Yes & 2 & Not done & SMP PTB \\
\hline 14 & Ophthalmology & Symptoms & ISC & 2 & 30 & $\mathrm{~F}$ & No & Not done & Not done & Mediastinal glands \\
\hline 15 & Orthpaedics & Symptoms & ISC & 3 & 30 & $\mathrm{M}$ & NK & 3 & 4 & Mediastinal glands \\
\hline 16 & NK & Symptoms & ISC & 3 & 47 & $\mathrm{M}$ & Yes & 2 & Not done & Mediastinal glands \\
\hline 17 & Surgery & Symptoms & White & 36 & 36 & M & Yes & "Pos" & Not done & Finger ulcer \\
\hline 18 & Medicine & Symptoms & ISC & 2 & 30 & $M$ & Yes & Not done & Not done & Nodes in axilla \\
\hline 19 & Paediatrics & $\begin{array}{l}\text { Community } \\
\text { contact screen }\end{array}$ & ISC & 2 & 30 & M & NK & Not done & 3 & Mediastinal glands \\
\hline 20 & Surgery & Symptoms & ISC & $<1$ & 29 & M & No & 4 & Not done & $\begin{array}{l}\text { Cervical lymph } \\
\text { nodes }\end{array}$ \\
\hline 21 & Surgery & Symptoms & ISC & 1 & 28 & $M$ & Yes & Not done & Not done & Pleural \\
\hline 22 & Anaesthetics & Symptoms & Egypt & 3 & 34 & M & Yes & 3 & Not done & Mediastinal glands \\
\hline
\end{tabular}

$\mathrm{ISC}=$ Indian subcontinent; $\mathrm{NK}=$ not known; $\mathrm{SMP} \mathrm{PTB}=$ sputum smear positive pulmonary tuberculosis.

Table 3 Other staff groups with tuberculosis

\begin{tabular}{|c|c|c|c|c|c|c|c|c|c|}
\hline $\begin{array}{l}\text { Case } \\
\text { no. }\end{array}$ & Specialty & Referral & $\begin{array}{l}\text { Ethnic } \\
\text { group }\end{array}$ & $\begin{array}{l}\text { Age } \\
\text { (years) }\end{array}$ & Sex & $\begin{array}{l}\text { Prior } \\
B C G\end{array}$ & $\begin{array}{l}\text { Heaf grade pre- } \\
\text { employment }\end{array}$ & $\begin{array}{l}\text { Heaf grade } \\
\text { at presentation }\end{array}$ & Diagnosis \\
\hline 23 & Mortuary attendant & Symptoms & White & 62 & $M$ & Yes & Not done & 1 & SMCP PTB \\
\hline 24 & Radiographer & Contact screen & White & 21 & $\mathrm{~F}$ & Yes & Not done & 3 & SMCP PTB \\
\hline 25 & Physiotherapist & Symptoms & Anglo-Indian (born UK) & 22 & $\mathrm{~F}$ & $\mathrm{NK}$ & & & SMCP PTB \\
\hline 26 & Theatre technician & Symptoms & ISC (UK 33 years) & 44 & $M$ & Yes & Not done & Not done & Pleural \\
\hline
\end{tabular}

$\mathrm{NK}=$ not known; SMCP PTB $=$ sputum smear negative culture positive pulmonary tuberculosis

given, or presumed tuberculous infection for which chemoprophylaxis was given. A health care worker was defined as anyone working in a National Health Service hospital whether employed by the National Health Service or by contracting agencies. Details of the cases were extracted from occupational health records, questionnaires sent to clinicians reporting on the registry, and from hospital case notes.

The size and composition of the hospital workforce in the West Midlands for non-medical staff was obtained from the statistical information unit in the Department of Health. ${ }^{56}$ Information on hospital doctors in the West Midlands was obtained from personal communication (D Hubbard, statistical information unit in the Department of Health, Leeds). Mid-period data were available (1993 for nonmedical staff and 1994 for medical staff).

The incidence of TB by age, sex, ethnicity, and social class in adults of working age in the West Midlands was calculated using numerator data from the 1993 national TB notification survey database and denominator data from the 1993 labour force survey (André Charlett, PHLS Communicable Disease Surveillance Centre, London). A wide age range (20-64 years) was used and there was no analysis of narrower age bands because of small numbers.
The ethnic groups were split into white, those from the Indian subcontinent (ISC) and other, and social class was in accordance with the Standard Occupational Classification. ${ }^{7}$ Health care workers were compared with a matched socioeconomic group rather than with the whole population, which would include poor and unemployed people who are likely to be at higher risk of tuberculosis.

Workforce and community incidences are reported per $10^{4}$ with $95 \%$ confidence intervals. The incidence rate ratios were calculated comparing the incidence of TB in health care workers with the incidence of TB in the general population restricted to the relevant age, ethnicity, social class, and sex where appropriate. The incidence rates were compared and the 95\% confidence intervals were computed based on the incidence rates being Poisson distributed. A $p$ value of less than 0.05 was considered significant.

\section{Results}

The relevant workforce in the West Midlands comprised 5840 doctors (1914 of ISC and other non-white ethnic origin), 39848 nurses, and 9683 staff in professions allied to medicine, scientific and technical departments. ${ }^{45}$ Of the 
Table 4 Staff in whom tuberculosis or tuberculosis infection was detected by occupational surveillance

\begin{tabular}{|c|c|c|c|c|}
\hline$f_{o b}$ & Ethnic group & Sex & Occupational surveillance & Outcome \\
\hline Nurse (case 8) & White & $\mathrm{F}$ & Seen as contact* & Tuberculoma (lung) \\
\hline Nurse (case 27) & White & $\mathrm{F}$ & Seen as contact** & Heaf seroconversion ( 0 to 4$)$ \\
\hline Doctor (case 20$)^{* * *}$ & ISC & $\mathrm{M}$ & Pre-employment Heaf test & Grade 4 Heaf \\
\hline Tuberculosis health visitor (case 28 ) & White & $\mathrm{F}$ & Pre-employment Heaf test & Heaf seroconversion ( 1 to 4 ) \\
\hline
\end{tabular}

Table 5 Incidences and rate ratios of TB in health care workers compared with the general population restricted to the relevant age, ethnicity, social class, and sex where appropriate.

\begin{tabular}{|c|c|c|c|c|c|c|c|}
\hline \multirow[b]{2}{*}{ Occupation } & \multirow[b]{2}{*}{ No } & \multirow[b]{2}{*}{ Ethnic group } & \multirow[b]{2}{*}{ Social class } & \multirow[b]{2}{*}{$\operatorname{Sex}$} & \multicolumn{3}{|c|}{ Incidence TB per $10000 /$ year ( $95 \%$ CI) } \\
\hline & & & & & Health care worker & General population & Rate ratio $(95 \% \mathrm{CI})$ \\
\hline Nurses & 8 & White and others (excluding ISC) & 2 & $\mathrm{~F}$ & $0.6(0.2$ to 1.0$)$ & $0.5(0.4$ to 0.6$)$ & $1.3(0.6$ to 2.7$)$ \\
\hline Nurses & 7 & White & 2 & $\mathrm{~F}$ & $0.6(0.2$ to 1.0$)$ & $0.2(0.1$ to 0.3$)$ & $2.4(1.1 \text { to } 5.5)^{*}$ \\
\hline Doctors & 13 & ISC and others (excluding white) & 1 & $M \& F$ & $17.0(7.8$ to 26.2$)$ & 11.8 (8.5 to 15.1$)$ & $1.4(0.8$ to 2.7$)$ \\
\hline Others & 4 & All & 2 & $M \& F$ & $1.0(0.02$ to 2.0$)$ & $0.6(0.5$ to 0.7$)$ & $1.6(0.6$ to 4.4$)$ \\
\hline
\end{tabular}

nurses, $88.9 \%$ were white and $88 \%$ were women.

There were 28 cases meeting the definition of TB in hospital health care workers (tables $1-3)$. Case ascertainment in this study was probably as complete as is reasonably possible. The occupational health department recording system yielded 22 cases, all of whom were also known to the Midland Thoracic Society rare respiratory diseases registry. The registry yielded a further six cases not known to an occupational health department (five doctors and a theatre technician). There were 26 cases of active TB requiring full chemotherapy and three cases with presumed tuberculous infection for which chemoprophylaxis was given, including one case (case 20) in both categories (table 4).

Of the 26 cases of active TB, 24 presented with symptoms. Occupational surveillance detected only one case of active TB and an additional three subjects who received chemoprophylaxis for presumed tuberculous infection (table 4).

The 26 cases of active TB comprised eight nurses, 14 doctors, and four others (tables 1-3). The annual incidence of TB in the workforce is summarised in table 5 . There were 13 men and 13 women, and their mean age was 36 years (range 21-62). Ethnic groupings were as follows: 10 white, 12 ISC, one Black Caribbean, one Malaysian, one Anglo-Indian, and one Egyptian. Of the 26 cases, 17 had had prior BCG, five had not, and in four cases we had no information.

Of the 26 cases, 11 were pulmonary and 15 extrapulmonary. Of the three pulmonary cases that were smear and culture negative, all had the diagnosis confirmed by histological examination of the excised tissue. Of the 15 extrapulmonary cases, five were diagnosed clinically whilst the others had bacteriological (seven cases) and/or histological (10 cases) confirmation of the diagnosis. All mycobacterial cultures isolated were fully sensitive to first line antituberculous drugs.

No health care worker was known to be HIV positive and none had AIDS. Five were infectious (four smear positive pulmonary and one laryngeal) and all except case 10 (radiotherapist) worked with general medical and elderly patients but not with children or known immunosuppressed patients. Screening of staff in contact with infectious health care workers yielded no secondary cases of TB or presumed tuberculous infection. No patient in contact with an infectious health care worker is known to have developed tuberculous infection or disease. We have no information as to the outcome of screening of community contacts.

\section{Discussion}

The annual incidence of TB in nurses was not significantly greater than that of a mixed ethnic group in the social class 2 working age population of the West Midlands (table 5). However, all except one of the eight nurses was white and born in the UK; the other came from the West Indies but had lived in the UK for over 20 years. The annual incidence of TB in white nurses was significantly greater than that of white females in the local social class 2 working age population. In addition, among the social class 2 working age population in the West Midlands, most cases of TB (74\%) are in non-whites, strikingly different from the ethnic composition of our group of nurses with TB. We therefore speculate that the nurses may have contracted TB in the course of their work. All, in various specialities, could have been exposed to patients with infectious TB and, indeed, five out of nine reported contact with sputum smear positive patients.

The annual incidence of TB in doctors was much higher than in nurses. However, all but one of the doctors were foreign born, principally in the Indian subcontinent (ISC), and their incidence was not significantly greater than in the ISC and non-white ethnic group social class 1 working age population in the West Midlands. We therefore feel that we are dealing with a high ethnic rather than an occupational risk and that these doctors had probably acquired infection abroad and developed reactivation, rather than acquired infection occupationally in the UK, although it is impossible to be certain about this. In addition, most of the 
doctors were fairly recent entrants to the UK and therefore in the period of maximum risk for development of TB. ${ }^{8}$ We have no information as to return visits abroad, another risk factor. ${ }^{9}$ The single case in a white doctor was that of a surgeon in whom DNA fingerprinting confirmed that his mycobacterial strain matched that of a patient with TB on whom he had operated.

Other staff groups with TB comprised a small heterogeneous group (tables 3 and 5). Some previous surveys found mortuary attendants and laboratory workers to be at increased risk. ${ }^{13}$ There was only one case of a mortuary attendant with TB in our study, but no laboratory workers. It is of note, however, that case 24 was a close domestic contact of a sputum smear positive case and case 25 had been in India one year before presenting with symptoms.

Pre-employment screening was particularly lax in doctors, with seven of the 14 doctors being unscreened. Had these seven been screened according to the present code of practice, ${ }^{10}$ four cases $(10,11,14$ and 19), of which two were infectious (cases 10 and 11), might have been detected earlier. On the other hand, most of the nurses had satisfactory pre-employment screening. Despite this, no case was detected in nurses at the pre-employment stage. However, this is not unexpected since the preemployment check serves mainly to identify subjects for BCG vaccination and to give appropriate advice to those previously infected. Since most cases of TB present with symptoms, there should be more emphasis on reporting of suspicious symptoms and a continued policy of BCG vaccination in Heaf negative previously unvaccinated subjects.

There has been a policy of BCG vaccination in schools in the UK for many years so most of the people entering employment in the health service will have been vaccinated. Hence it is not surprising that cases of TB occurred in previously vaccinated subjects, serving to remind us that BCG vaccination is less than $100 \%$ efficacious. ${ }^{11}$

In conclusion, case ascertainment via the Midland Thoracic Society rare diseases registry was considered to be as complete as is reas- onably possible. Most cases of TB were in nurses and doctors, more commonly in doctors. All but one of the doctors were foreign born and probably had reactivation of infection acquired abroad rather than infection occupationally acquired in the UK. All but one of the nurses, however, were UK born and may have had occupationally acquired disease, their incidence being higher than in the community. The other health care workers were a small heterogeneous group and their incidence was similar to that of the general population. In nurses with TB, pre-employment screening had been satisfactory but in other staff groups, particularly doctors, such screening was patchy and, had it been carried out to currently recommended standards, might have led to earlier diagnosis in two (of a total of five) cases who were infectious at the time of presentation. As most cases present with symptoms, there needs to be continued emphasis on prompt reporting of suspicious symptoms both before and during employment, and a continued policy of offering BCG vaccination to previously unvaccinated subjects who are Heaf negative before employment.

1 Lunn JA, Mayho V. Incidence of pulmonary tuberculosis by occupation of hospital employees in the National Health Service in England and Wales 1980-1984. F Soc Occup Service in England
Med 1989;39:30-2.

2 Capewell S, Leaker AR, Leitch AG. Pulmonary tuberculosis in health service staff: is it still a problem? Tubercle 1988 in health serv

3 Grist NR, Emslie JAN. Infections in British clinical laboratories, 1988-1989. F Clin Pathol 1991;44:667-9.

4 Meredith S, Watson J, Citron K, Cockcroft A, Darbyshire $\mathrm{J}$. Are healthcare workers in England and Wales at increased risk of tuberculosis? BMF 1996;313:522-5.

5 Government Statistical Service. NHS hospital and community health services non-medical staff in England: 1983-1993. Statistical Bulletin 1994:1-14.

6 Government Statistical Service. Health and personal social services statistics for England 1993. London: Department of Health, 1995

7 Office of Population Censuses and Surveys. Social classifications and coding methodology. Standard Occupational Slassification (Volume 3). London: HMSO, 1991.

8 Medical Research Council Tuberculosis and Chest Diseases Unit. National survey of notifications of tuberculosis in England and Wales in 1983. BMF 1985;291:658-61.

9 McCarthy OR. Asian immigrant tuberculosis: the effect of visiting Asia. Br $\mathcal{F}$ Dis Chest 1984;78:248-53.

10 Joint Tuberculosis Committee of the British Thoracic Society. Control and prevention of tuberculosis in the UK code of practice 1994. Thorax 1994;49:1193-200

11 Colditz GA, Brewer TF, Berkey CS, Wilson ME, Burdick E, Fineberg HV, et al. Efficacy of BCG vaccine in the prevention of tuberculosis: meta-analysis of the published literature. FAMA 1994;271:698-702 